\title{
Modelagem Multiescala do Acoplamento Hidro-Geoquímico Aplicado ao Sequestro Geológico de Dióxido de Carbono
}

\author{
Sidarta Araújo de Lima \\ Programa de Pós-Graduação em Matemática Aplicada e Estatística, UFRN \\ 59078-970, Natal, RN \\ E-mail: sidarta@ccet.ufrn.br
}

Eduardo Rangel Gomes July Herbert S. Mariano

Programa de Pós-Graduação em Matemática Aplicada e Estatística, UFRN

59078-970, Natal, RN

E-mail: eduardoufpa@gmail.com, julyherbert.jhsm@gmail.com

\begin{abstract}
$\underline{\text { RESUMO }}$
Os aquíferos e reservatórios de petróleo são formações bastante complexas resultantes de processos de natureza geológica que ocorrem numa escala de tempo de milhares de anos. Uma característica peculiar destes meios porosos é que os fenômenos envolvidos ocorrem em diferentes escalas temporais e espaciais. Além disso, o forte acoplamento e a não linearidade dos fenômenos envolvidos incorpora uma complexidade adicional. Portanto, a modelagem matemática e computacional do escoamento de fluidos, fenômenos geomecânicos, bem como processos geoquímicos nestas formações geológicas é um grande desafio atual nos domínios da computação científica, engenharias e indústria do petróleo.

Com a recente descoberta de petróleo na camada do pré-sal, é necessário o desenvolvimento de novas técnicas para a redução das emissões de dióxido de carbono na atmosfera, pois a exploração do pré-sal produzirá uma liberação anual de milhares de toneladas equivalentes de carbono. Para se ter uma idéia da potencial degradação ambiental, estudos iniciais demonstram que a exploração da camada pré-sal emitirá uma concentração de $\mathrm{CO}_{2}$ entre 3 e 4 vezes superior aos campos do pós-sal explorados atualmente. Uma alternativa bastante promissora para a diminuição dos impactos ambientais na exploração de hidrocarbonetos é o armazenamento do dióxido de carbono em formações geológicas. O armazenamento ou sequestro de carbono consiste na captura e imobilização desse gás através da injeção mecânica em locais que não interfiram drasticamente no ecossistema local e não possibilite riscos de vazamento. Para que o armazenamento de $\mathrm{CO}_{2}$ seja uma tecnologia viável, a estocagem deve ser assegurada por centenas ou milhares de anos. Além disso, é necessário ter pouco impacto ambiental, baixo custo operacional e estar de acordo com as leis ambientais nacionais e internacionais (MORO, 2006). Em geral, o armazenamento pode ser realizado em uma grande variedade de ambientes geológicos, tais como reservatórios de petróleo, jazidas de gás natural, minas de carvão e aqüíferos salinos profundos, etc. Em particular, os campos de petróleo do pré-sal demostram-se como potenciais locais de armazenamento de $\mathrm{CO}_{2}$ por serem formados por rochas de baixa porosidade e permeabilidade situadas na subsuperfície (cap rock).
\end{abstract}


Naturalmente, o estudo de viabilidade da estocagem de $\mathrm{CO}_{2}$ em aquíferos e reservatórios de petróleo demanda o desenvolvimento de modelos matemáticos e computacionais capazes de simular com acurácia as diferentes escalas temporais e espaciais do problema, bem como os diversos fenômenos acoplados e não lineares envolvidos. Um fator fundamental no estudo dos processos envolvidos na injeção do dióxido de carbono em formações geológicas é a correta compreensão das propriedades físico-químicas do gás. Por exemplo, em reservatórios de petróleo espera-se que a injeção de $\mathrm{CO}_{2}$ produza o deslocamento do fluido residente nos poros. A eficiência deste processo esta fortemente associada as características fisicoquímicas do $\mathrm{CO}_{2}$, bem como as condições de temperatura e pressão no interior do meio poroso. Neste trabalho propomos a modelagem computacional do acoplamento hidro-geoquímico em meios porosos. Postulamos as equações da hidrodinâmica e do transporte reativo do soluto considerando o meio poroso rígido. Para a descrição do acoplamento entre as fases consideramos a teoria termodinâmica e derivamos o algoritmo flash. O modelo matemático é discretizado utilizando o método de volumes finitos de alta ordem. Os resultados computacionais permitiram simular numericamente o fenômeno do sequestro geológico do dióxido de carbono em aquíferos e reservatórios de petróleo.

Palavras-chave: Sequestro de $\mathrm{CO}_{2}$, Método de Volumes Finitos, Transporte Reativo

\section{Referências}

[1] M. A. Mendes, Modelagem Computacional de escoamento Bifásico em Meios Porosos Heterogêneos com Acoplamento Geomecânico, tese de doutorado, LNCC, 2007.

[2] A. Kurganov and E. Tadmor. New high-resolution central schemes for nonlinear conservation laws and convection-diffusion equations. J. Comput. Phys, 160:241? 282, 2000.

[3] Obi, E. I. and Blunt, M. J., Streamline-based simulation of carbon dioxide storage in a North Sea aquifer, Water Resour. Res., vol. 42, 2006.

[4] Z. Chen, G. Huan, Y. Ma, Computational Methods for Multiphase Flows in Porous Media, Society for Industrial and Applied Mathematics, 2006.

[5] Prausnitz, J. M., Lichtenthaler, R. N., Azevedo, E. G., Molecular Thermodynamics of Fluid Phase Equilibria, Printice Hall, 2.ed., 1985. 